\title{
Los vidrios con inscripción grabada en Hispania: contexto, tipología y significado
}

\author{
The Roman engraved glasses in Hispania: \\ context, typology and interpretation
}

\section{JAVIER SALIDo DomíngueZ}

Departamento de Prehistoria y Arqueología, Universidad Autónoma de Madrid C/ Tomás y Valiente, s/n, Cantoblanco, E-28040 Madrid

pjaviers@hotmail.com

\section{Belén Madariaga García}

C/ Cabruñana 20, E-33402 Avilés

belenmadariaga@hotmail.com

La revisión de los vidrios con inscripción grabada documentados hasta el momento en la península ibérica nos ha permitido realizar un análisis de la procedencia, de la tipología de los recipientes, así como del significado de los mensajes. Localizadas en diferentes contextos, estas piezas nos ofrecen una información muy interesante sobre los gustos, los deseos y el concepto hedonista de la vida de las personas que los adquieren para sí o como preciado obsequio.

\section{PALABRAS CLAVE}

PRODUCCIÓN HISPANORROMANA, INSCRIPCIÓN GRABADA, VIDRIO, EPIGRAFÍA, VIDA COTIDIANA

The review of the glass with engraved inscription documented in the Iberian Peninsula has allowed us to analyze the origin, the typology of the recipients, as well as the meaning of the message of the inscriptions. Located in different contexts, these pieces offer us very interesting information about the tastes, desires and the hedonistic concept of the life of the people who acquire them for themselves or as a precious gift.

\section{KEY WORDS}

HISPANO-ROMAN PRODUCTION, ENGRAVED INSCRIPTION, GLASS, EPIGRAPHY, EVERYDAY LIFE 


\section{Introducción}

La identificación de un fragmento de vidrio con inscripción grabada en el yacimiento de la villa romana de Veranes (Gijón) nos planteó la necesidad de abordar una revisión de las inscripciones grabadas sobre este material en la Hispania romana, que permitiera ofrecer una visión de conjunto de este tipo de producciones, un estudio que planteamos en este trabajo. ${ }^{1}$

Las ventajas que ofrecían los recipientes de vidrio sobre otros materiales, a causa de su diversa gama cromática o a su transparencia, a la variedad formal, a los bellos efectos lumínicos y al hecho de tratarse de un material no poroso, que permitía una mejor conservación de productos cosméticos y alimentarios manteniendo al mismo tiempo el sabor o gusto de los líquidos que contenían, unido a la revolución que supuso la técnica del soplado hacia mediados del siglo a aC, que permitió abaratar los costes de producción y con ello facilitar su difusión, hicieron de este un material muy presente en la vajilla doméstica romana. No obstante, siempre convivieron las producciones de vidrios más comunes con otro tipo de piezas de lujo, solo accesibles a una élite social y económica, entre las cuales se encuadran las piezas con decoración e inscripciones grabadas.

Por todo esto, no es extraño que en las últimas décadas se haya generado un interés creciente por el estudio y la difusión de las colecciones de vidrios procedentes de los yacimientos de la Hispania romana, fundamentalmente a partir de la publicación del catálogo de la exposición Vidrio romano en España. La revolución del vidrio soplado (Fuentes et al., 2001) y la celebración de las «I Jornadas sobre vidrio en la España Romana», en la Real Fábrica de Cristales de La Granja (Segovia), pero también gracias a la publicación de monografías sobre los hallazgos de Zaragoza (Ortiz Palomar, 2001a) o de Galicia (Xusto, 1996; 2001) entre otras. Además, se ha producido un lento, pero progresivo, avance en el conocimiento de los centros producción hispanos (Sánchez de Prado y Cruz, 2014; Sánchez de Prado, 2018), a pesar de las dificultades para su identificación (Foy, 2000: 41) y la problemática que plantean los estudios arqueométricos por la distorsión que representan el comercio generalizado de la masa vítrea en bruto y la práctica del reciclaje (Cruz, 2011:84).

El catálogo y estudio de las inscripciones grabadas sobre vidrio en la Hispania romana es una aportación al mejor conocimiento de este tipo de material en el ámbito peninsular y las interesantes interrelaciones que se establecen con los datos conocidos sobre él en el conjunto del mundo romano.

1. Este trabajo se ha realizado en el marco del proyecto de investigación Formas de ocupación y organización del espacio en el norte peninsular: el territorio astur entre época antigua y medieval a través del registro arqueológico y paleoambiental [MINECO-17-HAR2016-78036-P], cuyo investigador principal es José Avelino Gutiérrez González. 


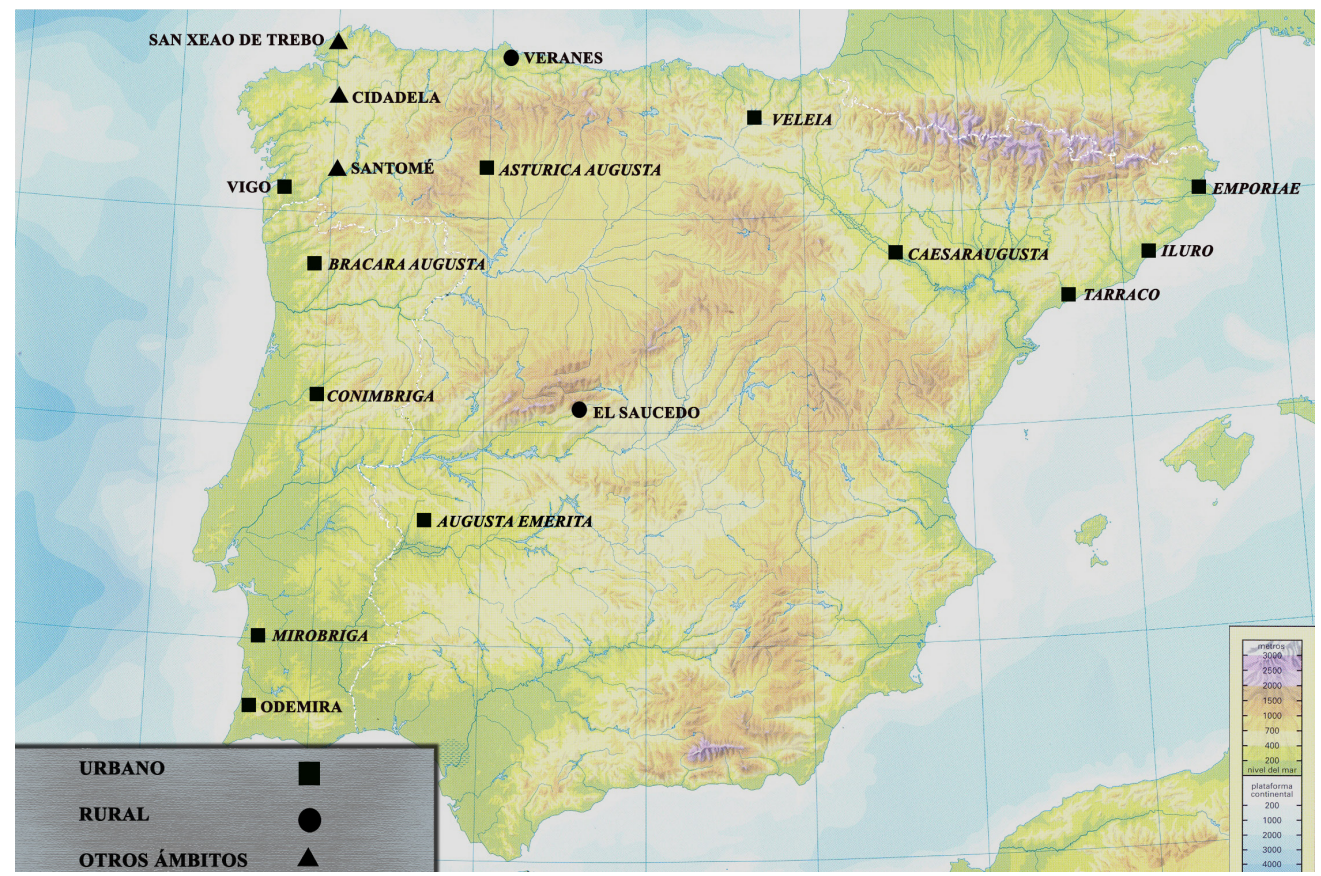

Figura 1. Mapa de distribución de los vidrios con inscripción grabada en Hispania.

\section{Catálogo y contexto arqueológico}

Presentamos a continuación el catálogo de los vidrios con inscripción grabada localizados en las provincias hispanas (fig. 1), clasificados según el tipo de ámbito donde se han localizado: urbano, rural y otros contextos. Hemos recopilado tanto aquellos publicados con detalle en monografías y artículos, incluyendo la pieza recientemente dada a conocer de las colecciones de la villa romana de Veranes (Gijón) (Salido y Madariaga, 2018), como otros simplemente citados y para los que no disponemos de descripción o reproducción gráfica. En este repertorio solamente tenemos en cuenta las inscripciones grabadas y excluimos las realizadas mediante la técnica del soplado en molde o la impresión, ya que difieren notablemente no solo en cuanto a técnicas de elaboración, sino también en lo tocante a su significado e interpretación (Foy y Nenna, 2006). Igualmente no prestamos atención a vidrios como los de Valentia (Álvarez et al., 2005: 257, fig. 7; Clariana, 2011 : 17, fig. 14), Elche (Ibarra Manzoni, 1879: 271, lám. XXV; Alarcão, 1970: 33; Balmaseda y Papí, 1998: 137-138, fig. 12), Clunia (Palol, 1991: pl. CLXXXIX; Morais, 2013: 129, fig. 8), Cástulo (Blázquez, 2015: fig. 2), Corduba (Castro et al., 2006: 110, lám. 8; Sánchez Ramos, 2007: 197-198, fig. 7) o Bracara Augusta (Cruz, 2011: 87, fig. 2) con representaciones de crismones, resultado de la combinación de las letras griegas X y $\Pi$ y flanqueados habi- 
tualmente por las letras A y $\Omega$, que requieren de un estudio específico por su especial significado.

\section{1. Ámbito urbano}

En ámbito urbano se ha localizado la mayor parte de las piezas con inscripción grabada y, además en el territorio de la provincia Tarraconensis proceden de ciudades de cierta categoría (fig. 2a y b, y tabla 1). En un lugar indeterminado de Emporiae (Empúries, Girona), quizás en el interior de una tumba situada entre la muralla occidental de la ciudad y la antigua carretera de Empúries, se localizó un ejemplar de las denominadas botellas puteolanas, que se encuadra dentro del tipo Isings 104 y fechado en los siglos III y IV dC, que conocemos bien gracias a la reproducción publicada por Gudiol (1936: 24, fig. 10). Conservado en la colección particular de D. ${ }^{a}$ Catalina Albert, García y Bellido (1954) tuvo ocasión de estudiar a fondo la inscripción y la iconografía. En él se representa, al igual que en otros vidrios de esta tipología, el puerto de Puteoli (Pozzuoli, Campania, Italia) y el tramo de costa hasta Baiae, nombre que figura en otros dos ejemplares (Astorga y Roma). Tanto la decoración como la inscripción se grabaron en el vidrio por abrasión o esmerilado a la rueda. Destaca en su iconografía la presencia del tramo final de un muelle, dos edificios representados de frente y, entre estas fachadas, un pórtico columnado y una empalizada debajo de él. La definición como OSTRIARIA no deja lugar a dudas sobre la presencia de un vivero en la escena. La inscripción distribuida en la pared del recipiente dice lo siguiente: [PIL]AE / STAG/NV NERONIS / OSTRIARIA / BAI[AE] RIPA (Gudiol, 1936: 24, fig. 10; García y Bellido, 1954: fig. 5; Vigil, 1969: 160, fig. 144) (tabla 1 n. ${ }^{\circ} 1$ y fig. 2a.1).

Durante las excavaciones llevadas a cabo en el solar de Can Cruzate, en la antigua Iluro (Mataró, Barcelona), también se halló en los estratos tardíos el fragmento de un vaso de vidrio Isings 1 16b, con una breve inscripción acompañada de una iconografía claramente cristiana, que permite sugerir un uso litúrgico, quizá como cáliz. En su parte exterior hay una escena grabada en la que se representa a un personaje barbudo flanqueado por dos símbolos estrellados y el nombre PETRVS, que identifica al personaje como el apóstol Pedro (Clariana, 2011: 4, fig. 11-12) (tabla 1 n. ${ }^{\circ} 2$ y fig. 2a.2).

Del basurero excavado en el forum provincial de Tarraco (Tarragona), procede un fragmento de plato de la primera mitad del siglo v dC, con decoración grabada que presenta motivos geométricos, vegetales y restos de una inscripción incompleta [...]A H[...] (Benet y Subias 1989: 334, fig. 184 y 189, ejemplar 9.27) (tabla 1 n. 3 y fig. 2a.3).

También en la provincia tarraconense, en Caesaraugusta (Zaragoza), se localizó un fragmento de vaso de vidrio de la forma Isings 116, forma mayoritariamente datada en el s. IV dC, con la inscripción incompleta grabada VI[...] / [...]T[...] (Beltrán et al., 1996: 134) (tabla 1 n. ${ }^{\circ} 4$ ).

En el País Vasco, procedente de la ciudad alavesa de Iruña (antigua Veleia), destaca un cuenco AR 59.1/Trier 15a, fechado en la primera mitad del siglo v dC y publicado 

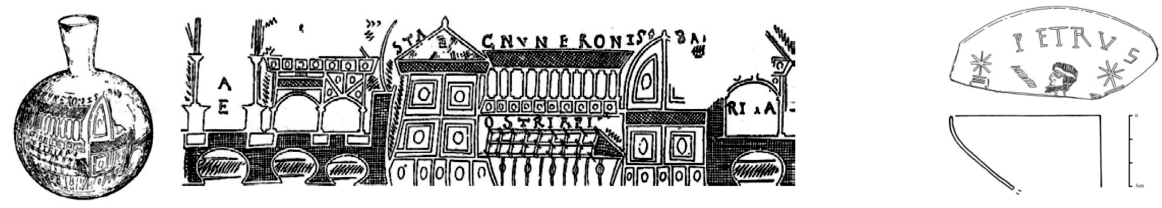

1

2
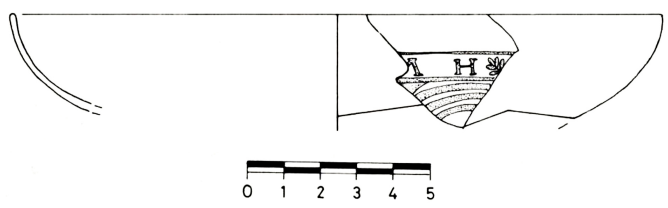

3

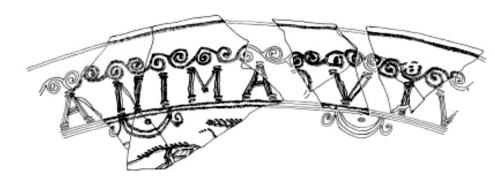

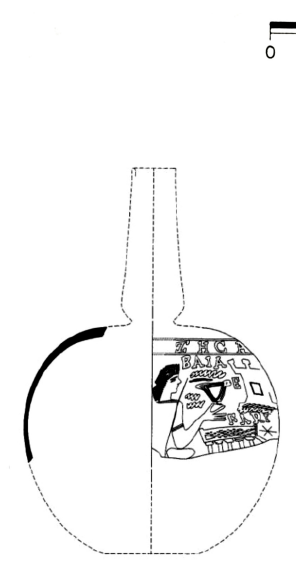

6

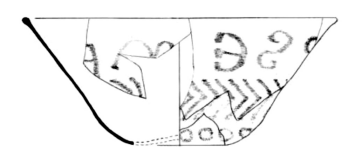

7

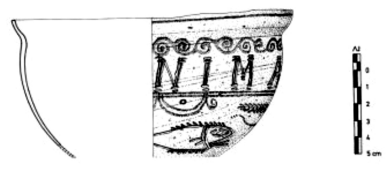

5

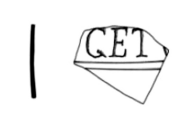

10

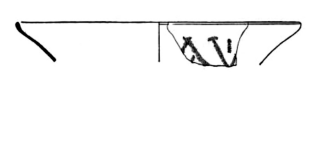

11

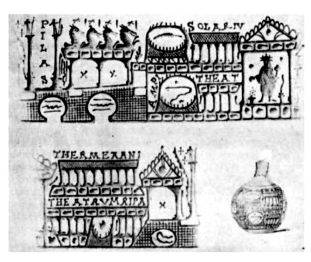

13

Figura 2a. Vidrios con inscripción grabada de ámbito urbano: 1. Emporiae (Empúries, Girona) (Gudiol, 1936, fig. 10). 2. Iluro (Mataró, Barcelona) (Clariana, 2011, fig. 11). 3. Tarraco (Tarragona) (Benet y Subias, 1989, fig. 184.9.27). 5. Veleia (Iruña, Álava) (Iriarte Kortazar, 2004, fig. 9). 6. Asturica Augusta (Astorga, León) (Amaré et al., 2003, fig. 2). 7. Vigo (Pontevedra) (Cruz 2009, vol. I, fig. 5.2.1.e.4; Cruz 2009, vol. II, fig. 6). 10. Bracara Augusta (Braga, Portugal) (Cruz 2009, vol. III, T197). 11. Conimbriga (Coimbra, Portugal) (Alarcão et al., 1976, pl. XLIV, n. ${ }^{\circ}$ 245). 12. Augusta Emerita (Mérida, Badajoz) (Bejarano, 2005, fig. 5b). 13. Odemira (Alentejo Litoral, Portugal) (García y Bellido, 1954, fig. 3). 
Tabla 1. Vidrios con inscripción grabada de ámbito urbano

\begin{tabular}{|c|c|c|c|c|c|c|c|}
\hline N. ${ }^{\circ}$ & Contexto & Provincia & Procedencia & Forma & Cronología & Inscripción & Bibliografía \\
\hline 1 & ¿Funerario? & Tarraconensis & Emporiae (Empúries, Girona) & $\begin{array}{l}\text { Botella puteolana, } \\
\text { Isings } 104\end{array}$ & S. III-IV dC. & $\begin{array}{l}\text { [PIL]AE / STA/GNV NERONIS / } \\
\text { OSTRIARIA / BAI[AE] RIPA }\end{array}$ & $\begin{array}{l}\text { Gudiol, 1936: 24, fig. 10; García y } \\
\text { Bellido, 1951: fig. 5; Vigil, 1969: 160, } \\
\text { fig. 144; Coelho, 2012: } 69 .\end{array}$ \\
\hline 2 & $\begin{array}{l}\text { Hábitat/ } \\
\text { ¿Ámbito litúrgico? }\end{array}$ & Tarraconensis & $\begin{array}{l}\text { Iluro (Mataró, Barcelona). } \\
\text { Solar de Can Cruzate }\end{array}$ & Vaso, Isings $116 \mathrm{~b}$ & S. v-vidC. & PETRVS & Clariana, 2011: 4, figs. 11-12. \\
\hline 3 & Basurero & Tarraconensis & $\begin{array}{l}\text { Tarraco (Tarragona). } \\
\text { Fórum provincial }\end{array}$ & Plato & $\begin{array}{l}\text { Primera mitad } \\
\text { del s. } v d C \text {. }\end{array}$ & $\ldots \mathrm{AH} \ldots$ & $\begin{array}{l}\text { Benet y Subias, 1989: 334, figs. } 184 \\
\text { y } 189 \text {, ejemplar 9.27. }\end{array}$ \\
\hline 4 & Hábitat & Tarraconensis & Caesaraugusta (Zaragoza) & Vaso, Isings 116 & S. Iv dC. & $\mathrm{VI}[\ldots] /[\ldots] \mathrm{T}[\ldots]$ & Beltrán et al., 1996: 134. \\
\hline 5 & Basurero & Tarraconensis & Veleia (Iruña, Álava) & Cuenco AR 59.1/Trier 15a & $\begin{array}{l}\text { Primera mitad } \\
\text { del s. v dC. }\end{array}$ & [A]NIMA...VI[VAS] & $\begin{array}{l}\text { Iriarte Kortazar 2004: 199, } 200 \\
\text { y 211, fig. } 9 .\end{array}$ \\
\hline 6 & Hábitat & Gallaecia & $\begin{array}{l}\text { Asturica Augusta } \\
\text { (Astorga, León) }\end{array}$ & $\begin{array}{l}\text { Botella puteolana, } \\
\text { Isings } 103\end{array}$ & $\begin{array}{l}\text { Mediados del } \\
\text { S. III - s. Iv dC. }\end{array}$ & $\begin{array}{l}{[\ldots] \mid ?[\ldots] \|[\ldots] \text { ZHCA[ ...] }} \\
\text { / BAIAE / FARI / DOLI[ARIVM] }\end{array}$ & $\begin{array}{l}\text { Amaré et al., 2003: 105-106; Cruz } \\
\text { 2009: vol. II, 298; vol. III, 78-79, } \\
\text { AstPB03. }\end{array}$ \\
\hline 7 & Productivo & Gallaecia & $\begin{array}{l}\text { Vigo, C/ Rosalía de Castro, } 9 \\
\text { (Pontevedra) }\end{array}$ & Vaso acampanado & S. v-vi dC. & SEMP[ER VIVAS] & $\begin{array}{l}\text { Cruz, 2009: vol. I, 249, fig. 5.2.1.e.4; } \\
\text { Cruz, 2009: vol. II, 169, 171, fig. 6; } \\
\text { Cruz, 2009: vol. III, 368, VigRcb01; } \\
\text { Barciela y Rey, 2016: 96-97. }\end{array}$ \\
\hline 8 & Hábitat & Gallaecia & $\begin{array}{l}\text { Bracara Augusta } \\
\text { (Braga, Portugal). Termas }\end{array}$ & Fragmento & S. Iv dC. & $\begin{array}{l}{[\ldots] \mathrm{A}[\mathrm{M} ? \ldots] /[\ldots \mathrm{Q} \ldots] /} \\
{[\ldots \mathrm{A} \ldots . .[[\ldots \mathrm{V} ? \mathrm{CT} \ldots]}\end{array}$ & Cruz, 2009: vol. III, 239-240, T183. \\
\hline 9 & Hábitat & Gallaecia & $\begin{array}{l}\text { Bracara Augusta, } \\
\text { Carvalheiras (Braga, Portugal) }\end{array}$ & Cuenco hemiesférico & S. iv dC. & Inscripción & Cruz, 2009: vol. III, 113, CARV250. \\
\hline 10 & Hábitat & Gallaecia & $\begin{array}{l}\text { Bracara Augusta (Braga, Portugal). } \\
\text { Termas del Alto da Cividade }\end{array}$ & Fragmento & S. III-IV dC. & {$[\ldots]$ GETV $[\ldots]$} & Cruz, 2009: vol. III, 241, T197. \\
\hline 11 & Hábitat & Lusitania & Conimbriga, (Coimbra, Portugal) & $\begin{array}{l}\text { Vaso, } \\
\text { Isings } 116\end{array}$ & S. Iv dC. & {$[\ldots] \mathrm{AV}[\ldots]$} & $\begin{array}{l}\text { Alarcão et al., 1976: 198, pl. XLIV, } \\
\text { n. }{ }^{\circ} \text { 245; Beltrán et al., 1996: } 134 .\end{array}$ \\
\hline 12 & Funerario & Lusitania & $\begin{array}{l}\text { Augusta Emerita, } \\
\text { (Mérida, Badajoz) }\end{array}$ & $\begin{array}{l}\text { Botella puteolana, } \\
\text { Isings } 103\end{array}$ & $\begin{array}{l}\text { Comienzos del } \\
\text { s. III - primera } \\
\text { década del s. Iv dC. }\end{array}$ & $\begin{array}{l}\text { [DUL]CIS ANIMA Z[E]SES } \\
\text { CONST[ANS?] / PVVTE]OLI, PVTE/ } \\
\text { OLI, CAVRVS, [FA]RI, ALOTIANA, } \\
\text { ANNIANA · STR[ATA POS FORV] } \\
\text { / PILAE / PORTVS / STADIVM / } \\
\text { CVRIONIANA / AMPI/THEAT/RV } \\
\text { / PALES/TRA / THERMAETANE } \\
\text { / THEA[TRVM] / O DIVM / } \\
\text { MACELLVM / ORTESIANA / } \\
\text { VICVI HVRANV / VICV MAGNV / } \\
\text { ENPORIVM / RIPA }\end{array}$ & Bejarano, 2005. \\
\hline 13 & ¿Funerario? & Lusitania & $\begin{array}{l}\text { Odemira } \\
\text { (Alentejo Litoral, Portugal) }\end{array}$ & $\begin{array}{l}\text { Botella puteolana, } \\
\text { Isings } 104\end{array}$ & $\begin{array}{l}\text { Finales del } \\
\text { s. III-s. Iv dC. }\end{array}$ & $\begin{array}{l}\text { PILAS / SOLARIV[M] / AMPI/ } \\
\text { THEAT[RVM] / THERM[A]E [I]ANI o } \\
\text { [TRAI]ANI / THEATRVM RIPA }\end{array}$ & $\begin{array}{l}\text { García y Bellido, 1954; Vigil 1969: } \\
\text { 160, fig. 145; Coelho, 2012: 64, } \\
66,72 \text { y ss. }\end{array}$ \\
\hline 14 & Hábitat & Lusitania & $\begin{array}{l}\text { Mirobriga (Santiago do Cacém, } \\
\text { Alentejo Litoral, Portugal) }\end{array}$ & Fragmento & S. Iv dC. & [PIE ZES]ES o [PIE Z]ES[ES] & $\begin{array}{l}\text { Pires, 1967: 108-110; Alarcão 1968: } \\
\text { 37-38; 1970: 33; Beltrán et al., } \\
\text { 1996: 134; Coelho 2012: } 123 .\end{array}$ \\
\hline
\end{tabular}


con gran detalle (Iriarte, 2004: 199, 200 y 21 1, fig. 9). La parte superior del recipiente, inmediatamente bajo el borde en cuarto de círculo, se decoró con roleos, realizados por abrasión y, debajo, tiene una inscripción en capitales cuadradas de doble línea, con ápices dobles, grabada con golpes desiguales de rueda estrecha, de la que se puede leer [A] NIMA...VI[VAS] (tabla 1 n. ${ }^{\circ} 5$ y fig. 2a.5). El cuenco presenta, además, una decoración formada por una doble línea horizontal de separación de la que pende una guirnalda semicircular de doble línea esmerilada, con una voluta en espiral a cada lado y en cuyo interior se realizó un pequeño círculo también esmerilado. Bajo la guirnalda se conserva un fragmento de la figura de un pez, del que son visibles la aleta dorsal en forma de crin, la agalla, parte de la aleta lateral y el ojo — con un iris romboidal esmerilado en su interior- ejecutado a golpes de rueda estrecha. A su derecha, se ve el extremo de un motivo vegetal, posiblemente una espiga, tallada con rueda estrecha $y$, bajo esta, el extremo de una ínfula obtenida por abrasión.

La presencia de vidrios con inscripción grabada es notable en el noroeste peninsular. Una botella Isings 103, de las calificadas como puteolanas, fue localizada en un complejo termal de dimensiones modestas situado en las proximidades del lienzo meridional de la antigua Asturica Augusta (Astorga, León), fechada entre mediados del siglo III y el siglo IV dC y conservada en el Museo de León. En esta fase bajoimperial, la estancia donde apareció la pieza, que cumplía la función de tepidarium, pasó a transformarse en un frigidarium (Amaré et al., 2003: 105-106; Cruz, 2009: vol. II, 298; vol. III, 78-79, AstPB03). La escena de banquete que decora la pared del recipiente está compuesta por una figura masculina que porta un scyphos; como telón de fondo se ejecutaron varias edificaciones y líneas onduladas, que representan las olas del mar debajo del término latino BAIAE, y un faro indicado con el vocablo FARI. Debajo de la palabra DOLI se aprecia la parte superior del frontón de un edificio porticado, quizás un DOLI[ARIVM]. La inscripción en griego que recorre la parte superior de la pared, del fragmento pequeño, [...]I? [...]II[...] y del grande [...]ZHCA [...], puede corresponder a una exhortación al disfrute de la vida (Amaré et al., 2003: 109) (tabla 1 n. ${ }^{\circ} 6$ y fig. 2a.6).

En el emplazamiento de las antiguas salinas altoimperiales localizadas en la calle Rosalía de Castro de Vigo, utilizado siglos después como espacio productivo, se excavó una oficina de producción vidriera de época tardoantigua donde se localizó un vaso acampanado con inscripción y decoración grabada, posiblemente fabricado en el mismo lugar, fechado entre los siglos v y vi dC y conservado actualmente en el Museo "Quiñones de León». Presenta en la parte inferior una banda de pequeños círculos; sobre ella, un motivo horizontal en espiga o espina de pez y, en la parte superior, bajo el borde, la expresión SEMP[ER VIVAS], realizada para ser leída desde el interior del recipiente y restituida gracias a las similitudes que presenta esta pieza con otra localizada en Holme Pierrepont (Nottingham, Inglaterra) (Cruz, 2009: vol. I, 249, fig. 5.2.1.e.4; vol. II, 169 y 171, fig. 6; vol. III, 368; Barciela y Rey, 2016b: 96-97) (tabla 1 n. ${ }^{\circ} 7$ y fig. 2a.7).

La mayor concentración de piezas de este tipo se halló en la ciudad romana de Bracara Augusta (Braga, Portugal) en diferentes contextos. Por un lado, un ejemplar en vidrio de 
color verde amarillento oscuro, fechado en el siglo IV dC, que presenta la inscripción grabada incompleta [...] A [M? ...] / [...Q...] / [...A...] / [...V?CT...] (Cruz, 2009: vol. III, 239-240, T183) (tabla 1 n. ${ }^{\circ} 8$ ). Por otro, un cuenco hemisférico del siglo IV dC, que presenta varias acanaladuras seguidas de una inscripción (Cruz, 2009: vol. III, 113, CARV250); se halló en la zona de Carvalheiras, lugar donde se construyeron unas termas públicas de medianas dimensiones sobre una antigua domus flavia (tabla 1 n. ${ }^{\circ}$ 9). Además, del edificio termal del Alto da Cividade, construido entre finales del siglo in e inicios del III dC, procede un fragmento de vidrio con la inscripción [...]GETV[...], datado en los siglos III y IV dC (Cruz, 2009: vol. III, 241, T197) (tabla 1 n. ${ }^{\circ} 10$ y fig. 2a.10).

También de Portugal, de la ciudad romana de Conimbriga (Coimbra), ya en el territorio de la provincia de Lusitania, procede el fragmento de vaso acampanado de la forma Isings 116 con inscripción grabada [...]AV[...] (Alarcão et al., 1976: 198, pl. XLIV, n. . 245; Beltrán et al., 1996: 134) (tabla 1 n. ${ }^{\circ} 11$ y fig. 2a.11), similar a uno de los fragmentos localizados en el yacimiento de Cidadela que ya hemos citado.

En Mérida (Badajoz), se localizó una ampulla del tipo Ising 103, del grupo de las llamadas botellas puteolanas, en una tumba de inhumación fechada entre comienzos del siglo III y la primera década del siglo IV dC. En la decoración grabada hay tres planos superpuestos con representaciones esquemáticas que corresponden a la visión de conjunto de una ciudad portuaria (Bejarano, 2005). La inscripción que encabeza el diseño dice [DUL]CIS ANIMA Z[E]SES CONST[ANS?]; debajo, y distribuida en el contorno de la pared, puede leerse una sucesión de términos: P[VTE]OLI, PVTE/OLI, CAVRVS; la palabra [FA]RI, asociada a una edificación coronada por tres almenas y con una puerta de acceso, identificable como faro, y las palabras ALOTIANA, ANNIANA - STR[ATA POS FORV], que hacen referencia a una sucesión de pórticos y estructuras. En el segundo cuerpo de la esfera también se observan diferentes construcciones con inscripciones asociadas. En la primera parte, sobre la estructura del muelle aparece la palabra PILAE, grabada en vertical y flanqueada por sendas columnas que soportan esculturas, con arcos triunfales a ambos lados, y hacia la derecha se halla el texto PORTVS, acompañado de la representación de dos naves sobre las olas del mar. El diseño continúa con un edificio identificado como STADIVM y la serie de construcciones designadas en la parte superior como ANNIANA·STR[ATA POS FORV]. En una segunda parte, que arranca bajo el texto PORTVS, aparecen una serie de edificios identificados COMO CVRIONIANA, AMPI/THEAT/RV, PALES/TRA, THERMAETANE, THEA[TRVM] y O DIVM. En la tercera y última parte pueden leerse los términos MACELLVM, ORTESIANA, sendos grupos de edificios designados como VICVI HVRANV y VICV MAGNV, y las palabras ENPORIVM y RIPA (tabla 1 n. ${ }^{\circ} 12$ y fig. 2a.12). Las inscripciones distribuidas en la pared del recipiente presentan particiones y algunas incorrecciones que delatan la necesidad de encajarlas en la compleja decoración monumental y la imposibilidad de rectificación, ya que tanto la decoración como las inscripciones se realizaron mediante la delicada técnica en frío de abrasión o esmerilado a la rueda.

Una botella muy similar a la anterior, igualmente del grupo de las puteolanas, y probablemente también procedente de un contexto funerario, se localizó en la ciudad lusitana de 
Odemira (Alentejo Litoral, Portugal), fechada entre finales del siglo III y el siglo IV dC, con decoración grabada e inscripciones con algunos términos ya mencionados en el ejemplar emeritense (García y Bellido, 1954; Vigil, 1969: 160, fig. 145; Coelho, 2012: 64, 72 y ss.). Alude la inscripción a las PILAS o columnas que sirven de sustento a sendas esculturas y siguen a la derecha cuatro edificios sumamente simplificados a manera de pórticos, identificados por las palabras SOLARIV[M] / AMPI/THEAT[RVM] / THERM[A]E [I]ANI o [TRAI]ANI / THEATRVM RIPA (tabla 1 n. ${ }^{\circ} 13$ y fig. 2a.13).

De Mirobriga (Santiago do Cacém, Alentejo Litoral, Portugal) procede un fragmento de vidrio con inscripción grabada, fechado en el siglo IV dC, que contiene la expresión [PIE ZES]ES o [PIE Z]ES[ES] (Pires, 1967: 108-110; Alarcão, 1968: 37-38; 1970: 33; Beltrán et al., 1996: 134; Coelho, 2012: 123) (tabla 1 n. ${ }^{\circ}$ 14).

\section{2. Ámbito rural}

Dos fragmentos de vidrio con inscripción grabada proceden de villae romanas del territorio tarraconense y lusitano, respectivamente. En la villa romana de Veranes (Gijón, Asturias) hemos podido analizar en detalle un fragmento de botella con inscripción grabada, cuyo depósito está fechado a finales del siglo Iv e inicios del siglo v dC (Salido y Madariaga, 2018), que ha servido de punto de inicio para la elaboración de este catálogo (tabla 2 n. ${ }^{\circ} 15$ y fig. 2b.15). El ejemplar lusitano, que presenta un texto muy fragmentario, pues conserva solo la letra final [...]A, procede del establecimiento rural de El Saucedo (Talavera la Nueva, Toledo) y está fechado en el siglo IV dC (Torrecilla, 2004: 335 y 348, lám. III, 21) (tabla 2 n. ${ }^{\circ} 16$ y fig. 2b.16).

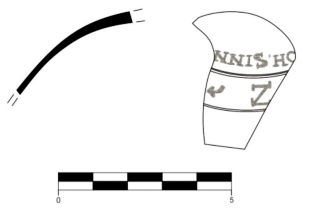

15

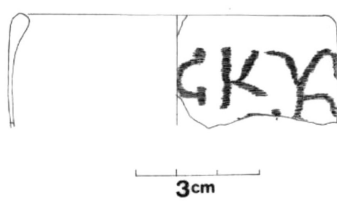

18

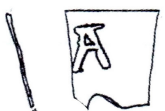

16

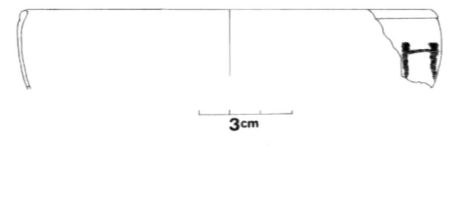

19

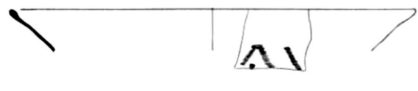

17

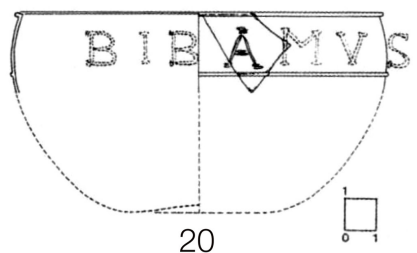

Figura 2b. Vidrios con inscripción grabada de ámbito rural: 15. Veranes (Gijón, Asturias) (Salido y Madariaga, 2018, fig. 3). 16. El Saucedo (Talavera la Nueva, Toledo) (Torrecilla, 2004, lám. III, 21). Vidrios con inscripción grabada de otros ámbitos: 17. Cidadela (Sobrado dos Monxes, A Coruña) (Cruz, 2009, vol. III, Cid03). 18. Cidadela (Sobrado dos Monxes, A Coruña) Názquez Martínez, 2005, fig. 21.91). 19. San Xiao do Trebo (A Coruña) Názquez, 2005, fig. 21.90). 20. Santomé (Ourense) (Xusto, 2001, fig. 79c). 
Tabla 2. Vidrios con inscripción grabada de ámbito rural

\begin{tabular}{|c|c|c|c|c|c|c|c|}
\hline N. ${ }^{\circ}$ & Contexto & Provincia & Procedencia & Forma & Cronología & Inscripción & Bibliografía \\
\hline 15 & Hábitat & Gallaecia & $\begin{array}{l}\text { Veranes (Gijón, Asturias). } \\
\text { Villa romana }\end{array}$ & $\begin{array}{l}\text { Botella, } \\
\text { Isings } 1030104\end{array}$ & $\begin{array}{l}\text { Finales del s. Iv - } \\
\text { inicios del s. v dC. }\end{array}$ & $\begin{array}{l}\text { [MVLTIS A]NNIS HO[MO } \\
\text { BONE / PIE] Z[ESES] }\end{array}$ & Salido y Madariaga, 2018. \\
\hline 16 & Hábitat & Lusitania & $\begin{array}{l}\text { El Saucedo (Talavera la Nueva, } \\
\text { Toledo). Villa romana }\end{array}$ & Cuenco o vaso & S. $n \mathrm{dC}$. & {$[\ldots] \mathrm{A}$} & $\begin{array}{l}\text { Torrecilla, 2004: } 335 \text { y } 348 \text {, } \\
\text { lám. III, } 21 .\end{array}$ \\
\hline
\end{tabular}

El fragmento fue localizado durante la campaña estival del año 2001 en la segunda terraza, del sector correspondiente a la logia abierta al sur (E11). Este bloque constructivo se levanta en el segundo proyecto constructivo de la villa, a partir de la primera mitad del siglo IV dC. Este sector se ocupó de manera continuada durante este siglo y el v dC. El vidrio procede de una unidad estratigráfica, que contiene materiales fechados en este momento, y destacan varios ejemplares de TSHT y una moneda datada en el año $383 \mathrm{dC}$ que nos aporta el terminus post quem de la formación o constitución del depósito. El perfil del fragmento, así como la disposición de la inscripción y las líneas que la delimitan, inducen a pensar que correspondería a la parte superior de una botella de cuerpo globular, como las formas Isings 103 o 104.

Tiene grabada una inscripción, distribuida en dos líneas, realizada sobre la superficie exterior mediante esmerilado o abrasión superficial del vidrio a la rueda. ${ }^{2}$ Presenta letras capitales cuadradas, rematadas en sus ángulos y extremos por refuerzos. En la primera línea se identifican las letras NNIS y HO, separadas por una interpunción circular que señala claramente la separación entre dos palabras. Por otro lado, la segunda línea conserva la letra Z, de mayor tamaño, precedida por una interpunción en forma de hoja de hiedra o hedera distinguens. Esta segunda línea de la inscripción se halla delimitada por tres finas líneas horizontales grabadas por arriba y dos finas líneas horizontales, por debajo, realizadas con un punzón metálico o de pedernal. La inscripción se ha podido restituir como [MVLTIS A]NNIS HO[MO BONE / PIE] Z[ESES].

\subsection{Otros ámbitos}

De Cidadela (Sobrado dos Monxes, A Coruña) (Caamaño y Fernández, 2002) proceden dos únicos fragmentos de vidrio con inscripción. De este asentamiento se han analizado tanto los vidrios de ventana (Caamaño y Vázquez, 2001) como la vajilla vítrea (Cruz, 2009). Los ejemplares son muy tardíos y presentan textos incompletos. Corresponden a un vaso acampanado con una inscripción realizada por abrasión, que reza [...]AV(?) [...], fechado entre la segunda mitad del siglo v d. y mediados del vi dC (Cruz, 2009: vol. II, 175,

2. El aspecto «piqueteado» de la superficie esmerilada, que se aprecia en fotografías de gran aumento, puede deberse a la erosión natural posdeposicional que sufren con mayor intensidad las superficies de los vidrios antiguos trabajadas mediante procedimientos en frío (Pilosi y Wypyski, 2002). 
Tabla 3. Vidrios con inscripción grabada de otros ámbitos

\begin{tabular}{|c|c|c|c|c|c|c|c|}
\hline N. ${ }^{\circ}$ & Contexto & Provincia & Procedencia & Forma & Cronología & Inscripción & Bibliografía \\
\hline 17 & Hábitat & Gallaecia & $\begin{array}{l}\text { Cidadela (Sobrado dos Monxes, } \\
\text { A Coruña) }\end{array}$ & Vaso acampanado & $\begin{array}{l}\text { Segunda mitad s. v } \\
\text {-mediados del s. vi dC. }\end{array}$ & {$[\ldots] \operatorname{AV}(?)[\ldots]$} & $\begin{array}{l}\text { Cruz, 2009: vol. II, 173-175, } \\
\text { fig. } 7 \text {; vol. III, 277-278, Cid03. }\end{array}$ \\
\hline 18 & Hábitat & Gallaecia & $\begin{array}{l}\text { Cidadela (Sobrado dos Monxes, } \\
\text { A Coruña) }\end{array}$ & $\begin{array}{l}\text { Cuenco, } \\
\text { Isings 85b }\end{array}$ & S. Iv-v dC. & {$[\ldots] \operatorname{CKY}[\ldots]$} & $\begin{array}{l}\text { Vázquez Martínez, 2005: 221, } \\
324,342,408 \text {, fig. } 21.91 \text {. }\end{array}$ \\
\hline 19 & Hábitat & Gallaecia & San Xiao do Trebo (A Coruña) & $\begin{array}{l}\text { Cuenco, } \\
\text { Isings } 85 \mathrm{~b}\end{array}$ & S. $I v-v d C$. & {$[\ldots] \mathrm{H}[\ldots]$} & $\begin{array}{l}\text { Vázquez, 2005: 134, 221, 342, } \\
\text { 408, fig. 21.90. }\end{array}$ \\
\hline 20 & Hábitat & Gallaecia & Santomé (Ourense). Castro & $\begin{array}{l}\text { Cuenco, } \\
\text { Isings } 96\end{array}$ & S. $111-\mathrm{v} d C$. & [BIB]AM[VS] & $\begin{array}{l}\text { Xusto, 2001: 406-407, fig. } \\
\text { 79.c. }\end{array}$ \\
\hline
\end{tabular}

Cid03; vol. III: 277) (tabla 3 n. ${ }^{\circ} 17$ y fig. 2b.17) y un cuenco tipo Isings 85 b, datado en los siglos IV-V dC y con inscripción grabada [...]CKY[...], igualmente realizada por abrasión (Vázquez, 2005: 221, 324, 342, 408, fig. 21.91) (tabla 3 n. ${ }^{\circ} 18$ y fig. 2b.18). Estos materiales debieron de corresponder a la población civil local que ocupó el emplazamiento del antiguo campamento cuando la unidad militar ya la había abandonado en el siglo IV dC (Fernández y Caamaño, 1996: 98; Costa y Varela, 2011: 183). Las estructuras documentadas no permiten determinar la entidad del poblamiento u ocupación de este período.

Del asentamiento costero de carácter indeterminado de San Xiao do Trebo (A Coruña) procede un fragmento de cuenco Isings 85b, fechado en los siglos IV y v dC, con inscripción grabada de la que solamente se conserva la letra [...]H[...] (Vázquez, 2005: 134, 221, 342, 408, fig. 21.90) (tabla 3 n. ${ }^{\circ} 19$ y fig. 2b.19). También ofrece un texto breve el fragmento de cuenco hemiesférico hallado en los niveles tardíos del castro de Santomé (Ourense), con dos letras grabadas restituidas como la expresión [BIB]AM[VS] (Xusto, 2001: 406-407, fig. 79c) (tabla 3 n. ${ }^{\circ} 20$ y fig. 2b.20).

\section{Estudio analítico de los vidrios hispanorromanos con inscripción}

El recuento de piezas de vidrio hispanorromano con inscripción grabada resulta francamente parco. No cabe duda de que debieron ser mucho más abundantes de lo que la documentación arqueológica permite apreciar, en parte debido a la fragilidad de este material, que habitualmente se halla muy fragmentado, y también debido a la sutilidad de las decoraciones e inscripciones grabadas, particularmente las realizadas mediante abrasión o esmerilado a la rueda, que pueden pasar fácilmente desapercibidas si no se estudian detalladamente y, sobre todo, si la superficie está alterada por algún tipo de corrosión. En definitiva, la revisión de la bibliografía disponible ha permitido identificar con seguridad un total de 20 ejemplares de vidrio con inscripción en las provincias hispanas (excluimos 
del inventario las piezas con crismones grabados y las inscripciones realizadas mediante otras técnicas, como ya se ha explicado), datados entre los siglos III y vi dC.

De ellos, la mayoría (10) proceden de la provincia Gallaecia, localizándose en menor proporción en la Tarraconensis (5) y en Lusitania (5); por el momento no se han documentado en la Baetica. Posiblemente estos hallazgos están en consonancia con la presencia en el noroeste de los dos centros de producción de vidrios hispanorromanos grabados reconocidos por el momento en la península Ibérica y que estarían localizados en las ciudades de Braga y Vigo. En el caso de Braga, este reconocimiento se justificaría por la identificación de producciones locales con decoraciones realizadas mediante grabado y abrasión, agrupadas bajo la denominación de taças paleocristãs (Cruz, 2011: 87-88), mientras que en el caso de Vigo estaría justificado por el hallazgo de una pieza con inscripción y decoración grabada, en el entorno mismo de una officina vidriera excavada en la calle Rosalía de Castro (Cruz, 2009: vol. I, 249 , fig. 5.2.1.e.4; vol. II, 169 y 171, fig. 6; vol. III, 368; Barciela y Rey, 2016: 94-95; 2016b: 96-97).

$\mathrm{Al}$ igual que en el resto del Imperio, los ejemplares hispanos aparecen repartidos tanto en ámbito doméstico y habitacional como en contexto funerario. A diferencia de lo que a priori se podría pensar, teniendo en cuenta los hallazgos históricos de piezas de este tipo en necrópolis, los del primer tipo constituyen una gran mayoría, si bien es verdad que se encuentran en mejores condiciones de conservación los recipientes localizados en ámbito funerario y permiten una mejor lectura, dada su menor fragmentariedad.

La revisión de los datos permite reconocer aspectos muy interesantes, como que la mayoría de las piezas (13) se han documentado en contextos urbanos, algunos procedentes de ambientes termales como los localizados en Bracara Augusta (Braga, Portugal) y Asturica Augusta (Astorga), aunque este último en contexto de basurero, y otros, en contexto funerario, como la botella puteolana de Augusta Emerita (Mérida). Aunque no hay datos seguros sobre su lugar de procedencia, posiblemente también se hallasen en tumbas los ejemplares de Odemira (Portugal) y Emporiae (Empúries, Girona). Resulta excepcional el caso ya mencionado del vaso acampanado identificado en un ambiente productivo de Vigo, por la posibilidad de haber sido elaborado en el mismo lugar.

Aunque algunos de los hallazgos verificados en ámbito urbano corresponden a ciudades de cierta entidad, como Emporiae (Empúries, Girona), Tarraco (Tarragona), Bracara Augusta (Braga, Portugal), Augusta Emerita (Mérida), Caesaraugusta (Zaragoza) o Asturica Augusta (Astorga, León), es cierto que también aparecen en urbes de menor categoría, como Mirobriga (Santiago do Cacém, Portugal), Odemira (Portugal) o Veleia (País Vasco). La fragmentariedad de este tipo de materiales, los problemas de conservación y las dificultades de identificación explican posiblemente la ausencia de vidrios con inscripción hasta el momento en conjuntos hispanorromanos de la importancia de Carthago Nova (Cartagena) o Corduba (Córdoba). Asimismo se han identificado recipientes vítreos con inscripción grabada en el ámbito castreño (Santomé, Ourense), en asentamientos productivos costeros (San Xiao do Trebo, A Coruña), en ocupaciones civiles de entidad desconocida sobre antiguos campamentos (Cidadela), así como en establecimientos rurales correspondientes a villae con vocación agropecuaria, como El Saucedo (Toledo) y Veranes (Gijón, Asturias). 
Señalamos este último ejemplar, porque se trata de una producción costosa, fruto de un comercio a larga distancia, que nos informa sobre el alto nivel adquisitivo de los propietarios de esta hacienda rústica (Salido y Madariaga, 2018).

Los tipos de recipientes identificados se encuadran fundamentalmente en las diversas variantes de cuencos hemiesféricos y vasos acampanados y en el grupo de las denominadas botellas puteolanas; los ejemplares que conservan el cuello y el borde permiten su clasificación formal dentro de los tipos Isings 103 y 104 . Hispania posee cuatro de las piezas identificadas de este tipo de ampullae o botellas bajoimperiales, halladas en Emporiae, Asturica Augusta, Augusta Emerita y Odemira. A estos ejemplares podría sumarse un fragmento de botella encontrada en la villa romana de Veranes.

El vidrio empleado en la fabricación de los recipientes es incoloro o de diferentes tonalidades verdes azuladas, verdosas o amarillentas, con pequeñas burbujas formadas en las diferentes fases del proceso de producción. El uso de los recipientes y su larga permanencia en un medio inadecuado han erosionado frecuentemente las superficies y provocado la pérdida de su transparencia original. Todas las piezas están realizadas mediante la técnica del soplado con caña al aire para definir el cuerpo y, en el caso de las botellas, modelando el cuello y el borde mientras la masa vítrea permanecía aún maleable. Estas piezas, elaboradas por los vidrieros o vitrarii, eran posteriormente decoradas por los diatretarii, artesanos especializados en el trabajo en frío mediante grabado, tallado y esmerilado o abrasión, así como en el pulido y afilado de las piezas (Ortiz Palomar, 2001 b: 53). Estas delicadas y laboriosas técnicas decorativas encarecían las piezas y las convertían en productos exclusivos destinados a una clientela de élite.

Si tenemos en cuenta las inscripciones y sus mensajes en combinación con la tipología de los recipientes, podemos destacar cuatro grupos claramente diferenciados.

El primer conjunto comprende los ejemplares localizados en Emporiae, Asturica Augusta, Augusta Emerita y Odemira. Estas piezas de origen italiano, que se integran dentro del tipo denominado "grupo Puteoli-Baiae», son ampullae del tipo Isings 103 o 104, fechadas en los siglos III y IV dC, que se han documentado en diferentes provincias romanas, como en la misma Italia (Populonia, Brescia, Ostia, Roma), en Germania (Colonia), en Britannia (York), un ejemplar custodiado en el Museo Nacional de Praga, otros tres identificados en la Colección Gorga y otra pieza procedente del norte de África (Painter, 1975; Ostrow, 1979; Morel, 1979; Ziviello, 1986; Roffia, 2002; Fujii, 2006), además de las hispánicas ya mencionadas. A este tipo de ejemplares podemos sumar quizás el fragmento de vidrio procedente de la villa romana de Veranes (Salido y Madariaga, 2018). Tanto el perfil del fragmento como la disposición de la inscripción que los recorre, y las líneas que la delimitan, inducen a pensar que correspondería a la parte superior de una botella de cuerpo globular, similar a las tipologías características de este grupo. La fragmentación de este ejemplar no permite saber si contaba con la característica decoración de escena portuaria.

Estas piezas presentan términos que hacen referencia a monumentos e infraestructuras de la costa de Baiae-Puteoli, combinadas en algunos casos con expresiones de buenos deseos y exhortaciones al disfrute de la vida, como en el caso de las piezas hispanas 
de Asturica Augusta, con el mensaje [DUL]CIS ANIMA Z[E]SES... (Bejarano, 2005) y de Augusta Emerita, con la expresión parcialmente conservada ZHCA[...]. En este sentido, el mensaje de la botella de Veranes, restituido como [MVLTIS A]NNIS HO[MO BONE / PIE] Z[ESES], manifiesta similar deseo hedonista de deleite y disfrute de la vida mediante la expresión «Bebe y vive muchos años, buen hombre» (Salido y Madariaga, 2018).

De confirmarse la pertenencia de este ejemplar al "grupo Puteoli-Baiae», estaríamos ante otra de las botellas que la mayor parte de los especialistas interpretan como piezas de recuerdo o souvenirs, ideadas para una clientela específica de alto nivel adquisitivo que visitaba las villae de su propiedad ubicadas en la costa campana y que, en algunos casos, solicitaban la inscripción de dedicatorias personalizadas para entregarlas como regalos a quienes las poseyeron finalmente (Picard, 1959: 29; Painter, 1975: 55, n. ${ }^{\circ} 2$; Ostrow, 1979 : 77; De Tommaso, 1994: 272-273; Paolucci, 2002: 15; Cooley, 2012: 109-111). Estos cinco ejemplares hacen de Hispania, por tanto, la provincia donde mayor cantidad de este tipo se ha localizado, junto con Italia.

A partir de los estudios realizados se ha concluido que los artesanos que elaboraban estas piezas no estaban necesariamente vinculados a un único taller de producción, aunque se ubicarían en lugares próximos a los mercados potenciales. La temática característica de este grupo de botellas ha llevado a suponer la localización de un área de producción en Roma o Campania, probablemente llevada a cabo por artesanos inmigrantes de las provincias orientales del Imperio (Paolucci, 2002: 13-15).

Los ejemplares hallados en contextos habitacionales y domésticos nos invitan además a reflexionar sobre el destino de los recipientes, que, a diferencia de los encontrados en contexto funerario, podrían utilizarse para el servicio de mesa o también como contenedores de productos cosméticos. ${ }^{3}$

Junto a estas producciones, nos encontramos con un segundo grupo de piezas tipológicamente identificadas como recipientes para beber, entre los que se distinguen diversas variantes de vasos acampanados y cuencos hemiesféricos, con similares inscripciones grabadas con expresiones de buenos deseos. Nos referimos a los ejemplares de las ciudades romanas de Veleia (País Vasco), Vigo (Pontevedra) y Mirobriga (Portugal) y del castro romano de Santomé (Ourense). El mensaje del cuenco de Veleia [A]NIMA...VI[VAS], que insiste en la idea del disfrute de la vida, está documentado en otros recipientes de vidrio como en la botella puteolana procedente de Piombino con el mensaje anima felix vivas (Painter, 1975: n. ${ }^{\circ}$ 1) o en un cuenco decorado con la técnica del fondo d'or de Farrobo (Faro, Portugal) de finales del siglo III-siglo IV dC con un mensaje similar: dvlcis vivas (Pires, 1967: 135-137; Alarcão, 1969: 71-79; Coelho, 2012: 122-123). Este mensaje está dedicado, al igual que el recipiente que lo porta, a su propietario aún vivo, a diferencia de la botella puteolana de Roma, destinada a una persona ya fallecida, como indica la expresión dedicatoria memoriae felicissime filiae (García y Bellido, 1954: 10, fig. 2).

3. En el caso concreto de la forma Isings 103, está documentado su uso para la conservación de productos cosméticos (Simon-Hiernard y Dubreuil, 2000: 175). 
El vaso hallado en Vigo presenta la inscripción SEMP[ER VIVAS], realizada para ser leída desde el interior del recipiente, y cuenta con el paralelo más directo en una pieza procedente de Holme Pierrepont (Nottingham, Inglaterra), que presenta una decoración de motivos vegetales y animales (Harden, 1956: 136, pl. 15g; Harden, 1959: 16, pls. 7, 8c; Barciela y Rey, 2016b: 96-97).

Más dudas ofrecen sobre su mensaje, dada su fragmentariedad, los ejemplares de Mirobriga con la expresión griega [PIE ZES]ES o [PIE Z]ES[ES] y de Santomé, con texto en latín restituido como [BIB]AM[VS]. Aunque resulta difícil aseverar la restitución de ambas inscripciones, estas se encuadran dentro de un tipo de mensajes muy frecuentes en recipientes de vidrio para beber, que hacen referencia al hedonismo y el ocio placentero y fugaz de la vida.

En este tipo de expresiones cabe destacar la fórmula griega PIE ZESES, adoptada y adaptada con éxito en el mundo romano, tanto en grafía griega como latina o mediante la combinación de ambas, y que aparece reflejada con frecuencia en las inscripciones documentadas en la vajilla vítrea de época romana. Se documenta incompleta en la botella de la ciudad hispanorromana de Asturica Augusta (Astorga), que incorpora dicha expresión combinando grafía latina y griega con sigma lunar (Amaré et al., 2003; Cruz 2009: vol. I, 277; vol. II, 298; vol. III, 79) y probablemente, también en el recipiente procedente de la villa romana de Veranes (Gijón) (Salido y Madariaga, 2018); además, es muy frecuente en vidrios localizados en otras regiones del Imperio, particularmente en los denominados fondi d'or (Lutraan, 2006; Howells, 2015). El mensaje Dignitas amicorum pie zeses vivas se grabó, por ejemplo, en un fondo d'or actualmente custodiado en el Corning Museum of Glass (Auth, 1996: fig. 5; Foy y Nenna, 2001: 219; Whitehouse, 2001: 249-250, pl. 842) y en la expresión cvm tvis/pie zeses en otra pieza similar del Metropolitan Museum of Art (VV.AA., 1962, fig. 6). Esta fórmula, con variantes, se repitió muy frecuentemente y se ha localizado en siete inscripciones de Roma (ICUR-03, 08482a; AE 1997, 168; ILCV 866 (em); ILCV 866a, c y d; ILCV 877), en una de Florencia (ILCV 866a) y en otra de Pésaro (ILCV 2212a). De nuevo, la fórmula aparece en el grabado del cuenco de mediados del siglo IV dC, con escena de caza, procedente de Wint Hill (Somerset, Inglaterra) y conservado en el Ashmolean Museum de Oxford, con el epígrafe vivas cvm tvis pie z(eses) (Harden, 1970: 63, fig. 7), idéntico mensaje al que aparece en una copa procedente de una tumba de Trasimeno (Umbría, Italia) (CIL XI, 8125, 2; Cooley, 2012: 110). La inscripción tallada en relieve también aparece de manera fragmentaria en un vidrio del siglo Iv dC, conservado en el Corning Museum of Glass, que dice: (pie) ze(sais) (Whitehouse, 1997: 65, fig. 76) y, de manera íntegra y grabada en grafía griega con sigma lunar, en un cuenco con decoración figurativa del mismo museo (Whitehouse, 1997: 268, 376, fig. 456), así como en el cuenco procedente de la región de Kertch, antigua Panticapea (Crimea), y conservado en el Louvre, que dicen pie zeses, ambos también datados en el siglo IV dC (Arveiller-Dulong y Nenna, 2005: 454, n. ${ }^{\circ}$ 1271, lámina 114), y en dos piezas de Colonia (Amaré et al., 2003: 113), una de las cuales se conserva en el Römisch-Germanisches Museum con la inscripción grabada pie zesais (Fremersdorf, 1939: lám. 42; Harden, 1959: 15, lámina VIIIa; 
Caron, 1997: 44). De Bonn (Alemania) procede otra pieza de la primera mitad del siglo IV dC con la expresión vivas cvm tvis p(ie) z(eses) (Follmann-Schulz, 1988; Chew, 2003: 102) $\mathrm{y}$, de Praga, la botella puteolana que inicia un largo texto con los términos felix pie zesaes cvm tvis (Coelho, 2012: 65; Cooley, 2012: 109), ambos en grafía latina. También presenta esta expresión con dedicación a determinadas personas en las inscripciones sobre vidrio CIL XV, 7012; CIL XV 7025; CIL XV, 7032 (cf. Cooley, 2012: 110). Una recomendación similar presenta el vaso diatreta de Colonia-Braunsfeld, actualmente expuesto en el RömischGermanisches Museum, con la expresión en caracteres griegos con sigma lunar (pi)e zesais kalos (Morin-Jean, 1977: 232, fig. 313; Arveiller-Dulong y Arveiller, 1985: 115). Un plato procedente de Roma con una escena anfiteatral de venatio presenta un texto parecido en grafía griega: pie zesais (Painter, 1989; Amaré et al., 2003: 113).

En las provincias orientales del Imperio también está presente el mismo mensaje en grafía griega sobre recipientes de vidrio, como los tres cuencos procedentes de Douch (Nenna, 2003: 369, fig. 25; 370, fig. 27; 2003b: 94-95, fig. 2.1) y el cuenco grabado de Kalabsha (Egipto), datados entre el siglo IV y principios del v dC (Nenna, 2003: 370, fig. 26), o el plato de la necrópolis egipcia de Wadi Quitma, del siglo IV dC (Amaré et al., 2003: 113). En el British Museum se conserva un cuenco con una inscripción tallada en relieve de la segunda mitad del siglo III-siglo IV dC procedente de Oxirrinco (Egipto), reflejada en grafía griega y uso de la sigma lunar, que dice (z)esais (Harden, 1936: 68; Nenna, 2003: 367, fig. 21). Presentan un texto parecido y grafía similar el recipiente de procedencia desconocida (quizá Siria o Palestina), fechado en el mismo período y actualmente depositado en el Ashmolean Museum de Oxford (Harden, 1970: 60, 63, fig. 6), y el de Hama, en Siria, que ahora se encuentra en el Metropolitan Museum of Art, de los siglos IV y v dC, que también rezan pie zeses (Caron, 1997: 42-44, fig. 59-62).

La misma expresión aparece grabada con grafía latina, manteniendo el mismo mensaje, en un cuenco bajoimperial de Ostia con el texto grabado bibe zeses (Morin-Jean, 1977: 163), en un recipiente de la Colección Getty, que contiene en la inscripción grabada la expresión vive zeses, o en el cuenco Isings 116 de la necrópolis de Saintes (CharenteMaritime, Francia) que repite la idea de vivir y disfrutar en latín y griego vivas cvm tvis omnibvs in deo z(eses) (Roger y Thomas, 1999: 112-114, fig. 5; Chew, 2003: 103), al igual que el cuenco de mediados del siglo IV dC de Augsburg (Alemania), decorado con las figuras de Adán y Eva y con texto vivas in deo p(ie) z(eses) (Bakker, 2001: 38; Chew, 2003: 102), y el cuenco de la necrópolis de Pallien (Trèves/Trier, Alemania), decorado con la escena del sacrificio de Isaac y con texto similar: vivas in deo z(eses) (Morin-Jean, 1977: 247; Chew, 2003: 96, fig. 5). Interesante también es el epígrafe CIL XV, 7048 de Roma, que dice [vi] vas multis annis pie/zeses.

Un tercer grupo está representado por un único ejemplar, localizado en Can Cruzate, en la antigua Iluro (Mataró, Barcelona), con una breve inscripción grabada con el nombre PETRVS, en referencia al personaje barbado que la acompaña, identificado como el apóstol del mismo nombre. El nombre del apóstol aparece documentado en fondi d'or, formando parte de inscripciones más largas acompañadas de iconografía de inequívoco 
carácter cristiano: un ejemplar custodiado en en el British Museum con la inscripción Petrvs/Pavlvs/Bicvlivs/dign[itas] [a]micorvm viv aspiezeses (Vopel, 1899: n. ${ }^{\circ} 333$; Morey, 1959: n. ${ }^{\circ}$ 314; Harden, 1987: 285; Lutraan, 2006: 134, c.81, fig. 49; Howells, 2015: 79, pl. 46, cat. n. ${ }^{\circ}$ 10); otro del Museo Nacional de Florencia que reza dignitas amicorvm vivas cvm tvis feliciter pie/Petrvs/Pavlvs (Vopel, 1899: n. 332; Morey, 1959: n. ${ }^{\circ} 241$; Lutraan, 2006: 133, c.79, fig. 48); una pieza del Museo de Arte de Pésaro que dice Petrvs cvm tuos omnes elares pie zeses (Vopel, 1899: n. ${ }^{\text {313 }}$; Morey, 1959: n. ${ }^{\circ}$ 235; Lutraan, 2006: 137, c.95); otra en la Pusey House de Oxford con la inscripción Pavlvs/Petrvs/dignitas amicorvm vivat(is in pa) ce dei ze(ses) (Vopel, 1899: n. ${ }^{\circ}$ 293; Morey, 1959: n. ${ }^{\circ}$ 388; Lutraan, 2006: 141, 152, c.111 x. c. 164), y otros cuatro ejemplares en la Biblioteca Apostólica Vaticana, con expresiones similares (Vopel, 1899; Morey, 1959; Lutraan, 2006). En este sentido, no son raros los ejemplos de recipientes de vidrio de época romana con decoración grabada o realizada mediante la técnica de los fondi d'or, tanto de temática pagana como cristiana, acompañada de inscripciones que identifican a los personajes representados.

Y el cuarto grupo comprende aquellas inscripciones incompletas de las que desgraciadamente apenas podemos extraer información sobre el destinatario, funcionalidad u objeto del mensaje. A este tipo corresponden las identificadas en los dos fragmentos de Cidadela (Sobrado dos Monxes, A Coruña), con un mensaje poco esclarecedor: [...]AV(?) $[\ldots]$ y $[\ldots]$ CKY $[. .$.$] . En esta última, la primera letra puede interpretarse como una C latina$ o una sigma lunar; la segunda es fácilmente identificable como la letra griega K (kappa), mientras que la última podría identificarse como las letras Y (ípsilon) o quizá también como una X (ji) griega, según se aprecia en el dibujo.

En este último grupo también se incluyen las piezas con mensajes irreconocibles hallados en Caesaraugusta: VI[...] / [...]T[...]; las tres localizadas en Bracara Augusta: [...]

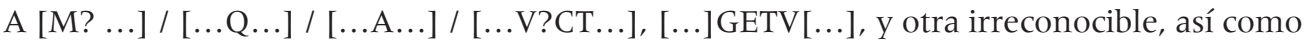
la pieza de Conimbriga con las letras $[\ldots] \mathrm{AV}[\ldots]$, similar a la citada de Cidadela.

Además, se incluyen los vidrios que solo conservan una letra grabada, como en el caso del fragmento hallado en la villa romana de El Saucedo (Talavera la Nueva, Toledo), con la letra [...]A, y el ejemplar del asentamiento costero ubicado en San Xeao de Trebo (A Coruña, Galicia) con la letra: $[\ldots] \mathrm{H}[\ldots]$, que podría identificarse con la letra griega eta.

\section{Conclusiones}

A partir del estudio de los ejemplares de vidrios hispanorromanos con inscripción grabada, hemos podido diferenciar cuatro grupos. El primero comprende las botellas puteolanas con decoración grabada, englobadas en el «grupo Puteoli-Baiae». El análisis de estas piezas arroja algunos datos interesantes sobre la comercialización de productos y mercancías de valor. Llama la atención que Hispania constituya una de las provincias donde más ejemplares de este tipo de botellas puteolanas han aparecido, junto con Italia. Se localizan 
además en ciudades de cierta categoría, pero también en otras que podríamos considerar secundarias. Sería francamente interesante que pudiera confirmarse la pertenencia a este grupo del fragmento de vidrio documentado en la villa romana de Veranes, pero en cualquier caso esta pieza nos informa de que nos hallamos ante la existencia de propietarios de establecimientos rurales en condiciones de costear mercancías exclusivas, llegadas desde la misma Italia, o de recibir estos souvenirs en honor a su prestigio.

Una parte de las piezas incluidas en el primer grupo comparte con el segundo conjunto, que comprende vasos y cuencos para beber, las inscripciones con referencias al disfrute de la vida, con mensajes tanto en latín como en griego y que nos informan de nuevo de cómo Hispania estaba inmersa en los circuitos de comercialización principales de estas producciones bajoimperiales.

Correspondiente al tercer grupo solo identificamos una pieza, que se inscribe dentro de la práctica habitual de acompañar las representaciones de personajes con los nombres que los identifican.

Por último, hemos distinguido en un cuarto grupo las piezas que, dada la parcialidad de los mensajes, no ofrecen más información que el hecho de que también contaban con inscripciones grabadas, que por el momento y por desgracia no podemos interpretar.

\section{Bibliografía}

ALARCÃO, J. de, 1968, Vidros romanos de Museus do Alentejo e Algarve, Conímbriga 7, 7-39.

ALARCÃO, J. de, 1969, Une coupe à fond d'or découvert à Farrobo, Journal of Glass Studies 10, 71-79.

ALARCÃO, J. de, 1970, Abraded and engraved late roman glass from Portugal, Journal of Glass Studies 12, 28-34.

ALARCÃO, J. de, DELGADO, M. y MAYET, F., 1976, Fouilles de Conimbriga VI, Céramiques diverses et verres, París.

ÀlVAREZ, N., BALLESTER, C., CARRIÓN, Y., GRAU, E., PASCUAL, G., PÉREZ, G., RIBERA, A. y RODRÍGUEZ, G., 2005, L'àrea productiva d'un edifici del fòrum de Valentia al baix imperi (segles IV-v), VI Reunió d'Arqueologia Cristiana Hispànica. Les ciutats tardoantigues d'Hispania: Cristianització $i$ topografia, Valencia, 251-260.

AMARÉ TAFALLA, M. T., ORTIZ PALOMAR, M.E. y PAZ PERALTA, J.Á., 2003, Un souvenir de Baiae en Asturica Augusta (Provincia Tarraconense, Hispania), Journal of Glass Studies 45, 105-113.

ARVEILLER-DULONG, V. y ARVEILLER, J., 1985, Le verre d'époque romaine au Musée archéologique de Strasbourg, París.

ARVEILLER-DULONG, V. y NENNA, M. D., 2005, Les verres antiques du Musée du Louvre II. Vaisselle et contenants du er siècle au début du VII siècle après J.-C., Musée du Louvrel Somogy, París. 
AUTH, S., 1996, Drink may you live: Roman motto glasses in the context of Roman life and death, Annales AIHV 13, 103-112.

BAKKER, L., 2001, Sündenfall in Augsburg, Archäologie in Deutschland 4, 38.

BALMASEDA, L. J. y PAPÍ, C., 1998, Cruces, incensarios y otros objetos litúrgicos de épocas paleocristiana y visigoda en el Museo Arqueológico Nacional, Boletín del Museo Arqueológico Nacional, tomo XVI, n. ${ }^{\circ} 1$ y 2 , 119-142.

BARCIELA, P. y REY, E., 2016a, Obradoiros de vidro en Vigo, en A. FERNÁNDEZ y P. BARCIELA (coords.), EMPORIVM. Mil anos de comercio en Vigo, Vigo, 94-95.

BARCIELA, P. y REY, E., 2016b, Cunca acampanada con inscrición, en A. FERNÁNDEZ y P. BARCIELA (coords.), EMPORIVM. Mil anos de comercio en Vigo, Vigo, 96-97.

BEJARANO OSORIO, A.M., 2005, Una ampulla de vidrio decorada con la planta topográfica de la ciudad de Puteoli, Mérida. Excavaciones Arqueológicas 2002, Memoria n. ${ }^{\circ}$ 8, 513-532.

BELTRÁN LLORÍS, M., ORTIZ PALOMAR, M. E. y PAZ PERALTA, J. Á., 1996, La vajilla relacionada con el vino en Hispania, en II Simposio Arqueología del Vino, Jerez, 129-200.

BENET, C. y SUBIAS, E., 1989, Els vidres, en Un abocador del segle $v d C$ en el Fòrum Provincial de Tàrraco, Memòries d'excavació 2, Taller Escola d'Arqueologia, Tarragona, 329-349.

BLÁZQUEZ MARTíNEZ, J. M., 2015, La Traditio Legis de Cristo a Pedro y Pablo en un plato de vidrio de Cástulo, Linares (Jaén), Espacio, Tiempo y Forma, 28, Serie II, Historia Antigua, 137-145.

CAAMAÑO GESTO, J. M. Y FERNÁNDEZ RODRÍGUEZ, C., 2002, Novedades sobre el campamento romano de A Cidadela: Sobrado dos Monxes, A Coruña, en A. MORILLO (ed.), Arqueología militar romana en Hispania, Madrid, 213-226.

CAAMAÑO GESTO, J. M. y VÁZQUEZ MARTÍNEZ, M. Á., 2001, El vidrio de ventana de época romana hallado en el campamento de Cidadela (Sobrado dos Monxes, A Coruña): Catálogo de piezas, Gallaecia 20, 205-216.

CARON, B., 1997, Roman Figure-Engraved Glass in The Metropolitan Museum of Art, Metropolitan Museum Journal 32, 19-50.

CASTRO, E., PIZARRO, G. y SÁNCHEZ, I., 2006, El conjunto arqueológico del Parque Infantil de Tráfico de Córdoba. La ocupación tardoantigua del suburbium occidental de Colonia Patricia Corduba, Annales de Arqueología Cordobesa 17, vol. II, 103-118.

CHEW, H., 2003, La Coupe gravée au sacrifice d'Abraham de Boulogne-sur-Mer, Pas-de-Calais (France), Journal of Glass Studies 45, 91-104.

CLARIANA, J.F., 2011, Sobre alguns vidres antics d'Iluro i el seu territorium, XXVII Sessió d'Estudis Mataronins 2010, 3-23.

COELHO, A. J. S. D., 2012, Testemunhos artísticos no vidro romano portugués, Dissertação de Mestrado em História da Arte da Antiguidade, Lisboa [en línea]. Disponible en <https://run.unl.pt/ handle/10362/7749>.

\section{COOLEY, A.E., 2012, The Cambridge Manual of} Latin Epigraphy, Cambridge.

COSTA, J. M. y VARELA, D., 2011, A Cidadela después de Roma: introducción al estudio del yacimiento y su entorno durante el período medieval, Gallaecia 30, 181-194.

CRUZ, M. da, 2009, O Vidro Romano no Noroeste Peninsular. Um olhar a partir de Bracara Augusta, Universidade do Minho, 2009 [en línea, consultado 11 febrero 2018]. Vol. I: Texto; Vol. II: Manual de formas; Vol. III: Catálogo. Disponible en <http://repositorium.sdum.uminho.pt/ handle/1822/9883>.

CRUZ, M. da, 2011, Fragmentos de vidro, fragmentos da memória. Aproximação à actividade vidreira em Bracara Augusta, CEM. Cultura Espaço \& Memória 2, CITCEM, 83-94.

DE TOMMASO, G., 1994, Vetri incise dalla Tuscia annonaria. Note sulla produzione di vetri incise tra III e IV secolo, ArchCl XLVI, 261-278. 
FERNÁNDEZ, C. y CAAMAÑO, J. M., 1996, El campamento romano de Cidadela (A Coruña, Galicia): Análisis del registro faunístico, Munibe 48, 93-104.

FOLLMANN-SCHULZ, A. B., 1988, Die römischen Gläser aus Bonn, Colonia.

FOY, D., 2000, Les indices d'une production de verre: repérages et interprétations; Étude méthodologique, l'exemple provençal, en P. CRESSIER (ed.), El vidrio en Al-Andalus, Madrid, 13-41.

FOY, D. y NENNA, M.-D., 2001, Tout feu, tout sable. Mile ans de verre antique dans le Midi de la France, Aix en Provenza.

FOY, D. y NENNA, M. D. (dirs.), 2006, Corpus des signatures et marques sur verres antiques, vols. I, II y III, Aix en Provenza.

FREMERSDORF, F., 1939, Römische Gläser aus Köln, Colonia.

FUENTES DOMÍNGUEZ, Á., PAZ PERALTA, J. Á. y ORTIZ PALOMAR, E. (eds.), 2001, Vidrio romano en España. La revolución del vidrio soplado, Real Fábrica de Cristales de La Granja.

FUJII, Y., 2006, Report on four Roman glass fragments from the Gorge collection: attribution to the Puteoli-Baiae Group, The $17^{\text {th }}$ Congress of the Association Internationale pour l'Histoire du Verre (AIHV), Amberes, 136-141.

GARCÍA Y BELLIDO, A., 1954, El vaso puteolano de Ampurias, Archivo Español de Arqueología 27, n. ${ }^{\circ} 89-90,212-226$.

GUDIOL RICART, J., 1936, Monumenta Cataloniae. Vol. III. Els vidres catalans, Barcelona.

HARDEN, D. B., 1936, Roman Glass from Karanis found by the University of Michigan Archaeological Expedition in Egypt 1924-1929, Ann Arbor.

HARDEN, D. B., 1956, Glass Vessels in Britain and Ireland, A.D. 400-1000, en D. HARDEN (ed.), Dark Age Britain: studies presented to E.T. Leeds, Londres, 132-170.

HARDEN, D. B., 1959, Highdown Hill Glass Goblet with Greek Inscriptions, Sussex Archaeological Collections 97, 3-20.
HARDEN, D. B., 1970, Ancient Glass, II: Roman, The Archaeological Journal CXXVI, 44-77.

HARDEN, D. B. (ed.), 1987, Glass of the Caesars, Milán.

HOWELLS, D. T., 2015, A Catalogue of the Late Antique Gold Glass in the British Museum, Londres.

IBARRA MANZONI, A., 1879, Illici: su situación y antigüedades, Alicante.

IRIARTE KORTAZAR, A., 2004, El vidrio romano tallado en Álava, Jornadas sobre el vidrio en la España Romana, Segovia, 191-211.

LUTRAAN, K. L., 2006, Late Roman GoldGlass: Images and Inscriptions, Thesis, McMaster University, Hamilton, Ontario.

MORAIS, R., 2013, Representações artísticas em vidros e cerâmicas romanas de Bracara Augusta, Revista da Facultade de Letras. Ciências e Técnicas do Património, Vol. XII, 127-142.

MOREL, J. P., 1979, La ceramica e il vetro, en F. ZEVI (ed.), Pompei 79, Nápoles, 241-264.

MOREY, C. R., 1959, The Gold-Glass Collection of the Vatican Library with Additional Catalogues of Other Gold-Glass Collections, Biblioteca Apostolica Vaticana, Vaticano.

MORIN-JEAN, J. A., 1977, La Verrerie en Gaule sous l'Empire Romain, París.

NENNA, M. D., 2003, Verres graves d'Égypte du $\mathrm{I}^{\mathrm{er}}$ au v $\mathrm{v}^{\mathrm{e}}$ siècle ap. J.-C., en Actes du Colloque AFAV, Monographies Instrumentum 24, Montagnac, 359-375.

NENNA, M. D., 2003b, Verreries de luxe de l'Antiquité Tardive découvertes à Douch, Oasis de Kharga, Égypte, in Annales du $15^{e}$ Congrès de l'Association Internationale pour l'Histoire du Verre, Nueva York, 93-97.

ORTIZ PALOMAR, E., $2001 \mathrm{la}$, Vidrios procedentes de la provincia de Zaragoza: el Bajo Imperio Romano: catálogo, fondos del Museo de Zaragoza, Zaragoza.

ORTIZ PALOMAR, E., 2001b, Definición, tecnología y fabricación del vidrio antiguo, en Vidrio romano en España. La revolución del vidrio soplado, Real Fábrica de Cristales de La Granja, 8-61. 
OSTROW, S. E., 1979, The topography of Puteoli and Baiae on the eight glass flasks, Puteoli, Studi di Storia Antica 3, 77-140.

PAINTER, K. S., 1975, Roman flasks with scenes of Baiae and Puteoli, Journal of Glass Studies 17, 54-67.

PAINTER, K. S., 1989, A fragment of a Glass Dish in the Antiquarium Comunale, Rome, Kölner Jahrbuch 22, 87-98.

PALOL, P. DE, 1991, Un vidrio tallado con temas cristianos de Clunia, Studia Varia Cluniensia, 347354.

PAOLUCCI, F., 2002, L'Arte del vetro inciso a Roma nel iv secolo d.C., Florencia.

PICARD, Ch., 1959, Pouzzoles et le paysage portuaire, Latomus 18, 23-51.

PILOSI, L. y WYPYSKI, M. T., 2002, Two roman engraved glasses in the Metropolitan Museum of Art, Journal of Glass Studies 44, 25-34.

PIRES, M. F. de M., 1967, Documentos arqueológicos para a história das origens do Cristianismo em Portugal, Coimbra.

ROFFIA, E., 2002, Alcuni vetri incisi, en Nuove ricerche sul Capitolium di Brescia. Scavi, studi e restauri, Milán, 413-434.

ROGER, J. y THOMAS, N., 1999, Une nouvelle nécropole antique suburbaine découverte à Saintes, Bulletin de la Société d'Archéologie et d'Histoire de la Charente-Maritime 26, 109-114.

SALIDO, J. y MADARIAGA, B., 2018, Fragmento de botella procedente de la villa romana de Veranes (Asturias, España), Journal of Glass Studies 60, 25-39.

SÁNCHEZ DE PRADO, M. D. y DA CRUZ, M., 2014, La producción de vidrio en Hispania. Una versión actualizada, XVIII CIAC: Centro y periferia en el mundo clásico, Mérida, 1393-1397.
SÁNCHEZ RAMOS, I., 2007, La cristianización de las necrópolis de Corduba. Fuentes escritas y testimonios arqueológicos, Archivo Español de Arqueología 80, 191-206.

SIMON-HIERNARD, D. y DUBREUIL, F., 2000, Verres d'Époque romaine. Collection des Musées de Poitiers, Poitiers.

TORRECILLA AZNAR, A., 2004, Los vidrios romanos de la Villa de El Saucedo (Talavera la Nueva, Toledo), Jornadas sobre el vidrio en la España Romana, Segovia, 323-349.

VÁZQUEZ MARTÍNEZ, M. A., 2005, El vidrio de época romana en la provincia de A Coruña, Universidad de Santiago de Compostela. Disponible en: <http://hdl.handle. net/10347/9716> (tesis doctoral).

VIGIL, M., 1969, El vidrio en el mundo antiguo, Madrid.

VOPEL, H., 1899, Die altchristlichen Goldgläser: ein Beitrag zur altchristlichen Kunst und Kulturgeschichte, Leipzig.

VV.AA., 1962, The Metropolitan Museum of Art. Guide to the Collections: Medieval Art, Nueva York.

WHITEHOUSE, D., 1997, Roman Glass in The Corning Museum of Glass, vol. I, Nueva York.

WHITEHOUSE, D., 2001, Roman Glass in The Corning Museum of Glass, vol. II, Nueva York.

XUSTO RODRÍGUEZ, M., 1996, El vidrio romano en la Galicia antigua: la colección de vidrio antiguo del Museo Arqueológico de Ourense, Santiago de Compostela.

XUSTO RODRÍGUEZ, M., 2001, O vidro provincial galaicorromano, Vigo.

ZIVIELLO, C., 1986, L'industria vitrari in Puteoli, Bollettino Flegreo, Rivista di Storia, Arte e Scienze 2, 71-75. 
